\title{
A Corpus Linguistic Study of 12-Step Program Literature
}

\author{
Margaret A. O'Hara ${ }^{1}$ and Cass Dykeman
}

\section{Oregon State University}

\section{A preprint}

\begin{abstract}
Research indicates that the language used in addiction matters; therefore, the purpose of this study was to examine whether differences in discursive and psychological processes exist in 12-step texts used for substance and behavioral addictions. Using a synchronic corpus linguistic design, writings on the first step of Alcoholics Anonymous, Debtors Anonymous, Gamblers Anonymous, Narcotics Anonymous, Overeaters Anonymous, and Sex and Love Addicts Anonymous were analyzed using LIWC2015. The loglikelihood ratio test was used to examine if differences exist between the six texts, with post hoc analysis to further examine differences. Bayesian information criterion was used to measure effect size, which ranged from weak to very strong. Statistically significant differences exist in analytic, authentic, emotion tone, first-person singular pronouns, first-person plural pronouns, third-person singular pronouns, third-person plural pronouns, male, and biological process words. Results demonstrate that differences exist in the broad psycholinguistic, specific linguistic, and psychological and physical process words used in the texts. This research is the first study to compare linguistic components of different 12-step programs, which often fill a gap created by lags in research. Findings may have relevance to writers of 12-step literature, clinicians who provide treatment, and researchers who study substance use and behavioral addictions, and individuals with these issues.
\end{abstract}

Keynotes: 12-step, addiction, behavioral addictions, corpus linguistics, LIWC

1. Correspondence concerning this article should be addressed to Margaret A. O'Hara at oharam@oregonstate.edu 


\section{A Corpus Linguistic Study of 12-Step Program Literature}

"A difference between mental illness and mental wellness is the ' $\mathrm{i}$ ' and the 'we.'

"The opposite of addiction is not sobriety. The opposite of addiction is connection" (TED, 2015).

"Together we could do what we could never do alone." "We had to hang together or die separately."

Community-journalist Sam Quinones (2015), the sole expert witness at a 2018 Senate hearing on the United States opiate epidemic, refers to it as the antidote. Alcoholics Anonymous (AA) knew the importance of community and modified language in its first publication to reflect this. Fifty years before Pennebaker Conglomerates (n.d.) shared their groundbreaking research on pronoun use, a New Jersey psychiatrist provided editorial advice on pronouns to AA founders. He strongly suggested changing use of the second-person pronoun you to the first-person plural pronoun, we to reflect community. Dr. J. W. Howard also recommended eliminating the word must and authoritarian tone. To remove all forms of coercion, he suggested changing from a you must to a we ought approach. "You may think you could find an easier, softer way. We doubt if you can" was changed to "We thought we could find an easier softer way. But we could not" (AA Cleveland, n.d., para. 1).

With addiction, the way out is rarely easy or soft and is often unclear due to conflicting information and stigma. There had been a disconnect between the research and clinical community and the recovery community (Best, 2017; Vederhus, Laudet, Kristensen, \& Clausen, 2010). There were calls for connection according to addiction research directors at UCLA and University of Pennsylvania (Toft, 2000), following calls for rigorous research on AA by the Institute of Medicine (1990). Studies supporting 12-step efficacy ensued (Humphreys, 2003; Kaskutas, 2009; Litt, Kadden, Kabela-Cormier, \& Petry, 2009; Owen et al., 2003; Project MATCH Research Group [PMRG], 1998). 
Two Harvard Medical School professors explained that "the addiction research field has moved beyond asking whether AA and 12-step treatment works, to investigating how and why they work" (Kelly \& Beresin, 2014, para. 18). Using criteria for determining effects in research (Hill, 1965), a causal pathway is supported by a preponderance of evidence that shows that AA attendance leads to abstinence (Krentzman et al., 2010). Increased abstinence is associated with participation in AA (Moos \& Moos, 2006). Mechanisms of behavior change and the effects of AA have been identified (Kelly, 2017). Researchers such as Kelly (2017) and Zemore (2017) suggest work on other "drivers of abstinence" in AA including neglected psychosocial factors such as positive emotions (Folkman, 2008; McHugh, Kaufman, Frost, Fitzmaurice, \& Weiss, 2013; Serafini, Malin-Mayor, Nich, Hunkele, \& Carroll, 2016; Vaillant, 2008), a variable in this study.

Another variable studied was Clout, which refers to leadership, confidence, and status portrayed through writing. Yet there is a destructive side of clout (Drouin, Boyd, \& Greidanus Romaneli, 2018; Drouin, Egan, Yergens, \& Hernandez, 2018). Increased understanding may aid those studying gaming disorder given that "clout" may be a driving force in the dark side of gaming, as evidenced by a report that a gamer's online clout went up after a prank 911 call on an opposing gamer led cops to draw fire and kill his opponent (Koerner, 2018).

The AA program is a model for 12-step programs where, for example, gamblers and debtors find relief. Over 400 groups have received permission from AA to adapt the Big Book and 12 steps (Anonymous, 2010). Research reported in the American Medical Association Journal of Ethics (Mendola \& Gibson, 2016) describe 12-step programs as useful for a wide range of addictions. Research and recovery communities agree that addiction is a chronic, progressive, fatal disease characterized by impaired control (Goldstein \& Volkow, 2011; Kalivas \& Volkow, 2005). The American Society of Addiction Medicine (ASAM) references substance use and other behaviors and includes food and sex in the official definition of addiction developed by 80 neuroscientists (ASAM, 2011). Raikhel (2015, p. 387) states that definitions evolve that translate prior 'failure of will' concepts to a 'language of self-control'-"the loss of which is seen as a core diagnostic criterion" (Baler \& Volkow, 2006; Weinberg, 2013). 
Impaired control is characteristic of substance and behavioral addictions (Dackis \& O'Brien, 2005; Fraser, Moore, \& Keane, 2014; Grant, Potenza, Weinstein, \& Gorelick, 2010). The American Psychiatric Association (APA) includes impaired control as a criterion for Gambling Disorder, the only behavioral addiction in the Diagnostic and Statistical Manual of Mental Disorders (5th ed.; [DSM-5]; APA, 2013). When revised, there was not sufficient evidence to include subcategories such as "sex addiction," "exercise addiction," or "shopping addiction" (APA, 2013, p. 481), though lay persons use these terms, and the afflicted are seen by clinicians. Time lags in research are estimated at 17 years (Slote Morris, Wooding, \& Grant, 2011). The slow recognition of behavioral addictions is filled in part by 12-step groups. A new disorder arrived on the scene. In 2018, the World Health Organization (2018) recognized gaming disorder. Not yet seen as a disorder by APA, internet gaming disorder is in the Conditions for Further Study section of the DSM-5 (APA, 2013) with lack of control as a criterion. With much unknown about behavioral addictions, research and recovery communities agree that control is impaired.

Furthermore, there is a "growing movement in the scientific and advocacy community to reframe the language of addiction" as outdated terminology does not reflect what scientists know about addiction (Gordon, 2016 , p. 3). Kelly joins others who have called for examining language use and suggest that investigation may reveal that treatment professionals and AA support the same underlying change processes (Dossett, 2017; Kelly, 2017; Kurtz, 2017). Hence, a study of the rhetorical and psychological processes of the first of the 12 Steps, wherein addressing lack of control is warranted.

To give context for the present study, a review of the literature is provided. Topic areas emerged from this review. These are: (a) descriptions of the 12-step programs studied; (b) a description of the first step; (c) historical accounts of the editorial process in the original manuscript of AA (Wilson, 2001), known as the Big Book, and (d) addiction studies using LIWC. Once addressed, the research questions of the study are described.

Literature from six 12-step programs were examined. The programs were AA, Narcotics Anonymous (NA), Gamblers Anonymous (GA), 
Overeaters Anonymous (OA), Debtors Anonymous (DA), and Sex and Love Addicts Anonymous (SLAA). They are community organizations founded in the U.S. that subscribe to a set of principles known as the 12 steps and 12 traditions. The principles vary by program with the basic structure preserved.

The original program is AA. It is the largest community-based program for alcohol-related problems (Greenfield \& Tonigan, 2013). It was founded in 1935 by Bill Wilson, a New York stockbroker and Bob Smith, an Ohio physician (AA, n.d.-b). Both struggled with alcoholism and prior to meeting had been to Oxford Groups, comprised of mostly non-alcoholics who used spiritual principles for daily living. Smith was not able to stop drinking until he met Wilson. Their meeting had an immediate effect and is considered the spark that began AA (AA, n.d.-b). One alcoholic helping another is the basis of the program. The 2018 estimate is 2 million members in 180 countries (AA, n.d.-a). "The only requirement for membership is a desire to stop drinking" (AA, 1981, p. 139).

The surrender process, including acknowledging lack of personal control, forms the basis of recovery in 12-step programs. Step One, termed the surrender step, states, "We admitted we were powerless over alcohol and that our lives were unmanageable" (AA, 1981, p. 21). It is weakness, not strength that undergirds 12-step recovery. Alcoholism is viewed as an incurable disease that can be arrested but not eliminated (Humphreys et al., 2004). Alcoholics are believed to have an allergy, meaning their bodies simply cannot tolerate alcohol (Franken, 2014). Willpower is considered to be of no use, regardless of the consequences; it is considered a progressive illness that combines a mental obsession with drinking and a physical sensitivity to alcohol (AA, 1952). The need to hit bottom is emphasized (AA, 1981). Bateson (1972) theorized that the reason AA worked was that members acknowledging powerlessness over alcohol experienced "a change in epistemology, a change in how to know about personality-in-the-world" that included acceptance of distinctly different assumptions (p. 313).

Anecdotal testimony about the effectiveness of AA had been responsible for its growth, though there has been an increase in research that supports AA and 12-step programs (Humphreys, \& Moos, 2001; Longabaugh, Wirtz, Zweben, \& Stout, 1998; Walitzer, Dermen, \& Barrick, 
2009; Zemore \& Kaskutas, 2009). In relation to the first step, Fiorentine and Hillhouse (2000a) concluded that people use a combination of 12-step and outpatient treatment as integrated activities and speculated that 12step philosophy is an accurate depiction of the nature of addiction, including powerlessness over substances (Fiorentine \& Hillhouse, 2000a). Fiorentine and Hillhouse (2000b) also determined that abstinence is more likely in individuals who accept powerlessness over alcohol and drugs.

Admission of powerlessness is the first step toward liberation from alcohol. The surrender process is also the first step toward liberation in programs modeled after AA. Narcotics Anonymous members admit powerlessness "over our addiction"; GA members admit powerlessness "over gambling"; OA members admit powerlessness "over food"; DA members admit powerlessness "over debt"; and SLAA members admit powerlessness "over sex and love addiction." The literature examined in this study was not the first 12-step literature to cover the concept of powerlessness.

Historical accounts of the editorial process in the original manuscript of AA, Alcoholics Anonymous (Wilson, 2001), known as the Big Book, will add context to the study. In 1937, with 40 sober members, Wilson and Smith decided it was time for a book (Anonymous, 2010). It was word-ofmouth up until that point, and the message varied. In 1939, the manuscript was ready for review. Four hundred copies were sent to the 100 AA members, friends, family, and medical and religious representatives. The original manuscript with handwritten changes reveals the discussions and debates that the feedback stimulated before the first printing six weeks later (Anonymous, 2010). Decades later, reviewers analyzing these edits found consistent themes, including shifts to descriptive language from prescriptive language, pronoun changes, efforts to minimize potentially offensive language, less emphasis on religion and more emphasis on the personal and universal regarding spirituality, ensuring consistency and efforts to engender cooperation and respect from a variety of professional disciplines (Anonymous, 2010).

The obvious Step One edit is the addition of the famous "we" in front of "admitted we were powerless over alcohol and that our lives were unmanageable" (Anonymous, 2010, p. 3). Oftentimes members refer to AA as a "we-program" signifying the importance of the community approach. 
The book's purpose changed from showing alcoholics how "they can recover" to how "we have recovered" (Anonymous, 2010). There were significantly more edits to first-person plural from singular and plural second- and third-person pronouns than any other edits, setting the voice of the text in first-person plural. The steps are introduced with "Here are the steps we took," (Wilson, 2001, p. 59) with White (1998) pointing out that we was most exclusively male and Caucasian (Maxwell, 1982) - hence, a reminder of the sociocultural era in which these publications were released. Though ethnicity variables are not included in the analysis software of this study, gender variables are examined. Research has shown that women may have concerns regarding the word "powerlessness" (Kaskutas, 1994; Krentzman, Brower, Cranford, Bradley, \& Robinson, 2012).

There is a growing body of research on LIWC (Pennebaker, Boyd, Jordan, \& Blackburn, 2015) as a methodology instrument used to study addiction. A literature review produced a representative sample, including articles in journals that focus specifically on addictions. The Psychology of Addictive Behavior, a journal of the American Psychological Association published a language analysis study (Collins et al., 2009) on the validity and clinical utility of mindfulness in relapse prevention. An expert panel generated two mindfulness-language (ML) dictionaries and compared ML in a mindfulness-based treatment manual to the Big Book (Wilson, 2001). Results supported ML for relapse prevention. Kornfield, Toma, Shah, Moon, and Gustafson (2018) examined whether language use in online discussions may predict relapse and found linguistic cues such as use of swear words.

Domestic and international LIWC studies exist in non-addiction journals. Couple-based interventions in alcohol use disorders is an area of study that utilizes LIWC. The University of Washington and the University of New Mexico are known for research on addictions.

Researchers at these schools, Hallgren and McCrady (2015), examined treatment outcomes using within-session language analysis. Their results support communal coping practices. Interestingly, the next volume of the same journal, included an article (Rentscher, Soriano, Rohrbaugh, Shoham, \& Mehl, 2017) by researchers at other United States universities who provided further evidence of the significance of communal coping through studying pronoun usage of individuals with problematic alcohol use. In the 
United Kingdom, Stephenson, Laszlo, Lefever, and Lefever (1997) examined diaries for correlations of therapy outcomes in 12-step residential treatment and Bliuc, Best, Iqbal, and Upton (2017) used LIWC to study a recovery initiative that sought to foster increased recovery capital through participation in an online recovery community.

The purpose of the study is to analyze the language used in 12-step literature to fill a gap and increase knowledge about language use that supports recovery for substance and behavioral addictions. Given the aforementioned literature review, three questions guided the study. The first research question was: Do differences in the level of broad psycholinguistic processes exist among the self-help textual materials? The second research question was: Do differences in specific linguistic categories exist among the self-help textual materials? The third research question was: Do differences in specific psychological and physical processes exist among these self-help textual materials?

\section{Method}

\section{Design}

This study employed a synchronic corpus linguistic design (Weisser, 2016). The corpora were drawn from the primary text for the following selfhelp groups: AA, NA, GA, OA, DA, and SLAA. The selection of AA was because it is the original program; NA because it is among the most wellknown 12-step programs (NIDA, 2013). In addition to programs that address substance use, a representative sample of programs that address behavioral addictions was sought. The GA program and text was selected because it addresses gambling, the only medically recognized behavioral addiction based on its inclusion in the DSM-5 (APA, 2013); OA because it is the most longstanding anonymous program that addresses food; DA because the researchers have concerns about how debt affects mental health (Lubin, 2011) and the lack of resources; and SLAA because it seems to be the most longstanding anonymous program that addresses sex (i.e., there is vagueness around the founding years of the other anonymous programs that address sex). The unit of analysis was individual words (Gabrielatos, 2018).

\section{Corpus}


Source texts. To construct the corpus, the researchers reviewed literature from 12-step programs to locate texts for comparison. Alcoholics Anonymous serves as the basis for the other programs so it was reviewed first. Opinions about which is the main text vary. Alcoholics Anonymous (Wilson, 2001), the Big Book, is the original book. It contains a description of the 12-step process followed by personal stories. The Twelve Steps and Twelve Traditions (AA, 1981), referred to as the Step Book was published 14 years later. The literature of the other 12-step programs more closely resembled the Step Book, therefore it was decided that it was more appropriate. The first step was examined.

Corpora construction. The section on the first step from each book was scanned and saved as a text file. The files were reviewed and cleaned according to LIWC2015 manual (Pennebaker et al., 2015) instructions. Spelling errors were corrected and hyphens that appeared but were not in the original texts were removed. The six documents were combined into one document with '\#' placed between each according to segmentation instructions in the LIWC2015 manual (Pennebaker et al., 2015).

\section{Measures}

Overview. The first four variables listed are summary variables, scaled from 0 to 100. Higher scores indicate higher degrees of variables. Each is a population-normed, composite variable, combining several LIWC2015 categories that reflect empirically-based constructs. The specific algorithms are proprietary, and therefore are not publicly available. The remaining variables are reported as a percentage of total words.

Pennebaker, Boyd et al. (2015) reported acceptable validity and reliability for all of the measures below.

Analytical thinking. Analytical thinking is a scale that measures formal, logical, and hierarchal thinking (Pennebaker, Chung, Frazee, Lavergne, \& Beaver, 2014). High scores reflect this pattern, whereas personal, informal, narrative thinking would yield low scores (Pennebaker, Booth, Boyd, \& Francis, 2015).

Clout. Clout is a variable that measures language indicative of social dominance and leadership (Drouin, Boyd, Hancock, \& James, 2017). 
When one communicates with confidence and conveys high expertise, such as those in positions of authority, there is a specific, consistent linguistic pattern that incorporates several LIWC2015 categories (Kacewicz, Pennebaker, Davis, Jeon, \& Graesser, 2014). High scores reflect this pattern, whereas lower scores reveal a more tentative, anxious style (Pennebaker, Booth et al., 2015).

Authenticity. Authenticity is a scale that combines scores on a number of variables. Higher scores are indicative of honest (versus deceptive) communication. It is based on research that identified how word patterns differ when subjects were lying from when they told the truth (Newman, Pennebaker, Berry, \& Richards, 2003; Pennebaker, 2011). When being dishonest people tend to use simpler language, more negative emotion words, and reference themselves less often (Newman et al., 2003). Possible scores on this scale range from 0 to 100 with higher scores reflecting more authentic and open language (Pennebaker, Booth et al., 2015).

Emotional tone. Emotional tone takes the negative emotion variable and the positive emotion variable and combines them into one summary variable (Cohn, Mehl, \& Pennebaker, 2004). A linguistic style that is emotionally positive would have high scores, whereas sad, anxious, or hostile tones would yield lower scores (Pennebaker, Booth et al., 2015).

First-person singular pronoun. First-person singular pronouns are used in place of a noun when there is personal reference to the speaker or writer. Examples include I, me, and mine.

Third-person singular pronoun. Third-person singular pronouns are used in place of a noun when there is reference to a person, animal, or thing other than the speaker or writer and reader or listener. Examples include she, her, and him.

Second-person pronoun. Second-person pronouns are singular or plural and are used in place of a noun to address the reader or listener. Examples include you and your. 
First-person plural pronoun. First-person pronouns are used in place of a noun when speaking or writing to a group that includes the speaker or writer. Examples include we, us, and our.

Third-person plural pronoun. Third-person pronouns are used in place of noun when there is reference to people, animals, or things other than the speaker or writer and reader or listener. Examples include they and their.

Impersonal pronouns. Impersonal pronouns do not refer to a particular person, animal, or thing. Examples include it and those.

Positive emotion. Positive emotions are defined as short-lived "multicomponent response tendencies" (Fredrickson, 2001, p. 218) or as pleasurable mental experiences (Cabanac, 2002). Examples include love and nice.

Negative emotion. Negative emotions are typically unpleasant emotions that are evoked in individuals to express a negative feeling towards a person or event. Examples include hurt and nasty.

Female references. Female references include nouns and pronouns. Examples include mom and her.

Male references. Male references include nouns and pronouns. Examples include boy and his.

Biological processes. Biological process words refer to the life processes of living organisms. Examples include eat, sex, and pain.

\section{Apparatus}

The text analysis software used to analyze the data for this study was the Linguistic Inquiry and Word Count 2015 (LIWC2015) program (Pennebaker, Booth et al., 2015). Text files were analyzed yielding scores for approximately 90 output variables. Each data record begins with the file name, word count, and four summary language variables (e.g., analytical, clout, authentic, and tone). Next, a general descriptor variable, 
words per sentence, is listed. These six variables are not reported as percentages. The remaining variables are calculated as a percentage of total words. These include two additional general descriptor variables (i.e., percentage of words with more than six letters and of words in the dictionary), 21 standard linguistic categories (e.g., percentage of pronouns), 41 word categories for psychological constructs (e.g., affect and biological processes), six personal concern variables (e.g., leisure activities), five paralinguistic categories (e.g., non-fluencies), and 12 punctuation variables (ex., commas).

\section{Data Analysis}

To answer the research questions, the log-likelihood ratio test (LL) was used to examine if differences exist between the six texts (Brezina, 2018). When an LL result was significant, post hoc analyses were conducted to examine difference between specific corpora. The post hoc testing procedure is identical to the overall log-likelihood ratio test, except word frequencies are regrouped to focus on specific corpora. If a category variable is found to be significant, six additional post hoc LL tests were conducted. To control the probability of falsely rejecting at least one null hypothesis in a family of $m$ hypotheses with an overall significance level of $\alpha=0.05$, the Bonferroni correction was applied such that each hypothesis was tested at an adjusted significance level of $\alpha_{\alpha}=\alpha / m$. The Bayesian information criterion (BIC) was used to measure effect size. Positive BIC values measure the strength of evidence against the null hypothesis; negative BIC values measure the strength of evidence in favor of the null hypothesis. The following descriptors for the absolute value of BIC were used: not worth more than a bare mention (0-2), positive evidence (2-6), strong evidence (6-10), and very strong evidence (>10) (Wilson, 2013). All analyses were conducted using $\mathrm{R}$.

\section{Results}

\section{Research Question 1 (Broad Psycholinguistic Processes)}

Differences in four broad psycholinguistic processes among the manuals were examined $(d f=5, \alpha \mathrm{a}=0.05 / 4=0.0125, c v=14.54)$. See Table 1 at the end of this chapter for results of significance testing for these 
elements. Post hoc testing for broad psycholinguistic processes ( $d f=1$, $\alpha \mathrm{a}=0.05 / 18=0.0028, c v=8.95)$ was conducted. See Table 2 at the end of this chapter for results of post hoc testing.

\section{Research Question 2 (Linguistic Processes)}

Difference in six linguistic processes among the manuals were examined $(d f=5, \alpha a=0.05 / 6=0.0083, c v=15.53)$. See Table 1 for results of significance testing for these elements. Post hoc testing for linguistic processes $(d f=1, \alpha \mathrm{a}=0.05 / 24=0.0021, c v=9.47)$ was conducted. See Table 2 for results of post hoc testing.

\section{Research Question 3 (Psychological and Physical Processes)}

Differences in five psychological/physical processes among the manuals were examined $(d f=5, \alpha a=0.05 / 5=0.01, c v=15.09)$. See Table 1 for results of significance testing for these elements. Post hoc testing for psychological/physical processes $(d f=1, \alpha a=0.05 / 12=0.0042, c v=8.21)$ was conducted. See Table 2 for results of post hoc testing.

\section{Discussion}

This study sought to explore word usage of self-help texts using the text for Step One in AA, DA, GA, NA, OA, and SLAA. Using the broad psycholinguistic categories of analytic, clout, authentic, and emotion tone words, the first research question examined whether differences exist in the self-help texts. Using the linguistic process categories of first-person singular pronoun, third-person singular pronoun, second-person pronoun, first-person plural pronoun, third-person plural pronoun, and impersonal pronouns, the second research question examined whether differences exist among these self-help texts. Using the psychological process categories of positive emotion and negative emotion and physical process categories of female, male, and biological process processes, the third research question examined whether differences exist in these self-help texts.

For analytic words, standard scores were lower than expected in GA and OA and higher than expected in SLAA. One possible reason for this finding is that GA and OA language is informal, whereas SLAA language is formal. An alternative explanation is related to the word count of each text, with lengthier texts affording more in-depth coverage of what Step 
One involves. Between the former and the latter, the latter is more likely as GA and OA are among the shorter texts, and SLAA is among the longer texts.

For authentic words, standard scores were lower than expected in AA, GA and OA, and higher than expected in DA and SLAA. One possible reason for the obtained results may have to do with stigma and shame, which may be higher for individuals with alcohol, gambling, or food addiction. In LIWC2015, the more a writer filters what they are writing, the lower the authenticity score and vice versa (Bulkeley \& Graves, 2018). Stigma and shame may affect the degree of openness. A second explanation may be related to how LIWC2015's authentic composite score was derived. This research showed that $I$ words were among those associated with truthtelling, as it indicates one is speaking from the heart (Jordan \& Pennebaker, 2017). The AA program, which served as a model to other anonymous programs, preferred we words over $I$ words as a means to convey a sense of community (Anonymous, 2010), not to avoid the truth. A third possible reason may be that because the LIWC2015 authentic variable is a composite score based on deception studies of individuals (Newman, Pennebaker, Berry, \& Richards, 2003; Pennebaker, 2011), it may not apply to self-help texts. Between the possible explanations, the third is more likely as research does not support the first explanation, and the second does not explain the variation of the results found.

For emotional tone words, standard scores were lower than expected in AA and GA and higher than expected in SLAA. One possible reason for the obtained results is related to changes in language use over time. The AA and GA texts were written decades before SLAA. An alternative explanation is that the tone of the AA text slanted negative due to Wilson's depression at the time he authored the text (AA, 1984). GA modeled its text after AA literature, as did SLAA; however, it was decades later when critiques of the book were promulgated (AA, 1984). It is possible SLAA writers referenced these critiques when writing their own literature. Between the former and the latter, the latter is more likely as Wilson's depression is well-documented.

For first-person singular pronouns, scores were lower than expected in SLAA and higher than expected in DA. One possible reason for the obtained results may have to do with research showing increased use of 
first-person singular pronouns with depression (Rude, Gortner, \& Pennebaker, 2004). Individuals in debt may be more depressed than individuals with sex and love addiction. An alternative explanation is the increased use of first-person singular pronouns in SLAA's first step may be for the purpose of helping members confront denial and identify with the thought patterns of others prior to recovery. Between the former and the latter, the latter is more likely as most of the first-person singular plural references in the step are in a paragraph with quotes such as, "If $I$ could only get the tax authorities (or my spouse/partner or my boss or these creditors) off my back, I'd be fine" (DA, 2016, p. 4).

For third-person singular pronouns, scores were more than expected in AA. One possible reason for this finding is related to psychological correlates of word use categories. Tausczik and Pennebaker (2010) attributed social interests and social support with the third-person singular linguistic category. An alternative explanation is that the obtained results are due to high rates of male third-person singular pronouns (he, him, his), which may be related to the higher prevalence of men identified with problematic alcohol use at the time the AA literature was written (Maxwell, 1982; White, 1998). Between the former and the latter explanations, the latter is most likely because at the time that AA literature was published there were higher prevalence rates of males with AUD seeking help (Maxwell, 1982; White, 1998). An example in the text is, "he would return to us convinced. He had hit bottom as truly as any of us" (AA, 1981, p. 23).

For first-person plural pronouns, scores were lower than expected in AA, and more than expected in NA. One possible reason for the obtained results may be related to the psychological correlate of social connection (Tausczik \& Pennebaker, 2010), specifically that it is greater in NA than in AA. An alternative explanation relates to the evidence that shows a decrease in first-person plural pronouns with depression (Rude, Gortner, \& Pennebaker, 2004). Bill Wilson was depressed for several years leading up to the writing of the AA text that is the subject of this study, which, according to AA history, is in contrast to the joy he felt upon writing the Big Book (AA, 1984). Between the former and the latter, the latter is more likely. In an AA publication, Pass It On: Bill Wilson and the AA Message (1984), Wilson is quoted as saying, "I've had a dreadful hex about further 
writing. Figure I had been so beat up by the events of these last years that I could never bring anything more off that would be worthwhile" (p. 355).

For third-person plural pronouns, scores were higher than expected in AA. One possible reason for the obtained results concerns out-group awareness (Tausczik \& Pennebaker, 2010). An example from the text is, "Many less desperate alcoholics tried AA, but did not succeed because they could not make the admission of hopelessness" (AA, 1981, p. 23). An alternative explanation is that the authors were aware of the health benefits of varying pronoun use, referred to as perspective switching (Jin, 2005; Campbell \& Pennebaker, 2003; Seih, Lin, Huang, Peng, \& Huang, 2008), specifically in relation to the third-person perspective (Kross, Ayduk, \& Mischel, 2005). Between the former and the latter, the latter is more likely because even though the research on the perspective switching came decades after the text was written, editors of AA writings were astute to the power of pronoun usage (Anonymous, 2010). Furthermore, the quote above is the only out-group reference in the text. An example of perspective switching is, "Alcoholics who still had their health, their families, their jobs, and even two cars in the garage, began to recognize their alcoholism" (AA, 1981, p. $23)$.

For male words, usage was more than expected in AA. One possible reason for this obtained result is that an approach that may be considered masculine is more effective to address AUD. An alternative explanation is related to the fact that AA literature was written decades ago and, as previously stated, was representative of the higher prevalence of men coming forward for help at that time (Maxwell, 1982; White, 1998). Between the former and the latter, the latter is more likely as noted in the aforementioned explanation.

For biological process words, scores were lower than expected in DA and higher than expected in OA and SLAA. One possible reason for this result is related to the era that each program was founded. Of the six anonymous programs studied, the three most recently formed showed difference. An alternative explanation is related to the nature of the addiction each text represented. The behaviors that lead one to DA are financial in nature, whereas the behaviors that lead one to OA and SLAA are physical in nature. A review of the texts shows that between the former 
and the latter, the latter is more likely as evidenced by quotes from each text. "The certain pain of continuing our sex and love addiction brought us to the admission of Step 1" (Augustine Fellowship, 1986, p. 72). "We hid from our pain by eating compulsively" (OA, 2018, p. 6).

Although results of this study advanced knowledge of the language of addiction, there were limitations. One limitation is that the LIWC2015 scores for analytic, clout, authentic, and tone do not reflect actual usage, but instead rely on a nontransparent LIWC2015 algorithm derived from large comparison samples. The outcome scores for these categories show where each standard score fell on a normal curve based on prior research. The non-transparency of the algorithm is a limitation for the researcher as it creates an element of uncertainty. In terms of external validity, results from this study were specific to the texts analyzed and therefore are not generalizable.

The literature presented has shown that the language of addiction matters. Clinical and research implications were drawn from this study. This research is the first study to compare linguistic components of different 12-step programs. Findings may have relevance to writers of 12-step literature, clinicians who provide treatment, researchers who study substance use and behavioral addictions, and individuals with these issues. Research demonstrates that differences exist in the broad psycholinguistic, specific linguistic, and psychological and physical process words used in the texts studied. From a global perspective, it is interesting that AA has the most difference compared to the other texts. The opposite would be expected. For six variables, scores were either more or less than expected. This result is surprising. Perhaps the other 12-step programs that depend on AA literature are not modeling their texts as closely as expected.

The implications for specific variables were expected and unexpected. It makes sense that there would be more biological process words in OA and SLAA versus GA due to the former being more physical in nature and the latter being financial. The fact that first-person singular words would be greater in DA and NA, which may represent more isolative behaviors, than SLAA, which may involve others, also makes sense. Furthermore, it is wellknown that AA literature is male-based. Research has shown that AA is effective for women in different ways from men (Kelly, 2013). Additional 
recognition of how male-dominated the AA literature is may support a call for changes to better represent AA membership. A surprising finding was that AA had fewer than expected first-person plural pronouns, given how much attention was devoted to use of we words in AA's original manuscript, The Big Book. In fact, differences in three different types of pronoun use were found in AA. The aforementioned influence of Wilson's depression on his writing or skill in pronoun use for perspective switching may be reasons. Further research may shed light on these results. It is difficult to make inferences based on the broad psycholinguistic process studied due to the limitation referenced above. It may be interesting to examine use of $I$ words, which correlate with truth-telling, versus use of we words, which support community, when authors have a choice in whether to communicate from the first-person singular or first-person plural perspective. Finally, across all the corpora, Clout was very high with scores over 92 on a percentile rank scale. This result was not discussed as there was no statistical difference per the nature of the research questions of this study. However, the reasons for such high Clout levels may represent an important area for future research. 


\section{References}

Alcoholics Anonymous. (1952). A.A. - 44 questions. New York, NY: Alcoholics Anonymous World Services.

Alcoholics Anonymous. (1981). Twelve steps and twelve traditions. New York, NY: Alcoholics Anonymous World Services.

Alcoholics Anonymous. (1984). Pass it on: The story of Bill Wilson and how the AA message reached the world. New York, NY: Alcoholics Anonymous World Services.

Alcoholics Anonymous. (n.d.-a). A.A. around the world. Retrieved from https://www.aa.org/pages/en_US/aa-around-the-world

Alcoholics Anonymous. (n.d.-b). Historical data: The birth of A.A. and its growth in the U.S./Canada. Retrieved from https://www.aa.org/pages/en_US/historical-data-the-birth-of-aaand-its-growth-in-the-uscanada

Alcoholics Anonymous Cleveland. (n.d.). Why Big Book manuscript edits were so vital. Retrieved from https://www.aacle.org/big-bookmanuscript-edits-vital/

American Psychiatric Association. (2013). Diagnostic and statistical manual of mental disorders (5th ed.). Washington, DC: Author.

American Society of Addiction Medicine. (2011). Definition of addiction. Chevy Chase, MD: Author. Retrieved from www.asam.org/researchtreatment/definition-of-addiction

Anonymous. (2010). The book that started it all: The original working manuscript of Alcoholics Anonymous. Center City, MN: Hazelden.

Augustine Fellowship, Sex and Love Addicts Anonymous, Fellowship-Wide Services, Inc. (1986). Sex and Love Addicts Anonymous. Boston, MA: Author.

Baler, R. D., \& Volkow, N. D. (2006). Drug addiction: The neurobiology of disrupted self-control. Trends in Molecular Medicine, 12, 559-566. https://doi.org/10.1016/j.molmed.2006.10.005

Bateson, G. (1972). The cybernetics of "self": A theory of alcoholism. Psychiatry, 34, 1-18. https://doi.org/10.1080/00332747.1971.11023653

Best, D. (2017). Why the mechanisms of 12-step behavior change should matter to clinicians. Addiction, 112, 938-939. https://doi.org/10.1111/add.13631 
Bliuc, A. M., Best, D., Iqbal, M., \& Upton, K. (2017). Building addiction recovery capital through online participation in a recovery community. Social Science \& Medicine, 193, 110-117. https://doi.org/10.1016/j.socscimed.2017.09.050

Brezina, V. (2018). Statistics in corpus linguistics: A practical guide. Cambridge, UK: Cambridge University Press.

Bulkeley, K., \& Graves, M. (2018). Using the LIWC program to study dreams. Dreaming, 28, 43-58. https://doi.org/10.1037/drm0000071

Cabanac, M. (2002). What is emotion? Behavioural Processes, 60, 69-83. https://doi.org/10.1016/S0376-6357(02)00078-5

Campbell, R. S., \& Pennebaker, J. W. (2003). The secret life of pronouns: Flexibility in writing style and physical health. Psychological Science, 14, 60-65. https://doi.org/10.1111/1467-9280.01419

Cohn, M. A., Mehl, M. R., \& Pennebaker, J. W. (2004). Linguistic markers of psychological change surrounding September 11, 2001.

Psychological Science, 15, 687-693. https://doi.org/10.1111/j.09567976.2004.00741.x

Collins, S. E., Chawla, N., Hsu, S. H., Grow, J., Otto, J. M., \& Marlatt, G. A. (2009). Language-based measures of mindfulness: Initial validity and clinical utility. Psychology of Addictive Behaviors, 23, 743-749. https://doi.org/10.1037/a0017579

Dackis, C., \& O'Brien, C. (2005). Neurobiology of addiction: Treatment and public policy ramifications. Nature Neuroscience, 8, 1431-1436. https://doi.org/10.1038/nn1105-1431

Debtors Anonymous. (2016). The twelve steps, twelve traditions, and twelve concepts of Debtors Anonymous. Needham, MA: Debtors Anonymous General Service Board.

Dossett, W. (2017). A daily reprieve contingent on the maintenance of our spiritual condition. Addiction, 112, 942-943. https://doi.org/10.1111/add.13731

Drouin, M., Boyd, R. L., \& Greidanus Romaneli, M. (2018). Predicting recidivism among internet child sex sting offenders using psychological language analysis. Cyberpsychology, Behavior, and Social Networking, 21, 78-83.

https://doi.org/10.1089/cyber.2016.0617

Drouin, M., Boyd, R. L., Hancock, J. T., \& James, A. (2017). Linguistic analysis of chat transcripts from child predator undercover sex stings. 
The Journal of Forensic Psychiatry \& Psychology, 28, 437-457. https://doi.org/10.1080/14789949.2017.1291707

Drouin, M., Egan, V., Yergens, N., \& Hernandez, E. (2018). "I'm 13. I'm online. U believeme?": Implications for undercover internet stings. Psychology, Public Policy, and Law, 24, 80-92. https://doi.org/10.1037/law0000149

Fiorentine, R., \& Hillhouse, M. P. (2000a). Drug treatment and 12-step program participation: The additive effects of integrated recovery activities. Journal of Substance Abuse Treatment, 18, 65-74. https://doi.org/10.1016/s0740-5472(99)00020-3

Fiorentine, R., \& Hillhouse, M. P. (2000b). Exploring the additive effects of drug treatment and twelve-step involvement: Does twelve-step ideology matter? Substance Use and Misuse, 35, 367-397. https://doi.org/10.3109/10826080009147702

Folkman, S. (2008). The case for positive emotions in the stress process. Anxiety, Stress, and Coping, 21, 3-14. https://doi.org/10.1080/10615800701740457

Franken, N. (2014). Applying the communication theory of identity to members of Alcoholics Anonymous: A phenomenological analysis of the expression of the recovery experience (Doctoral dissertation). Retrieved from https://mospace.umsystem.edu/xmlui/handle/10355/44464.

Fraser, S., Moore, D., \& Keane, H. (2014). Habits: Remaking addiction. New York, NY: Palgrave Macmillan.

Fredrickson, B. L. (2001). The role of positive emotions in positive psychology: The broaden-and-build theory of positive emotions. American Psychologist, 56, 218-226. http://doi.org/10.1037/0003066X.56.3.218

Gabrielatos, C. (2018). Keyness Analysis: nature, metrics and techniques. In C. Taylor \& A. Marchi (Eds.), Corpus approaches to discourse: A critical review (pp. 225-258). Oxford, UK: Routledge.

Gamblers Anonymous. (n.d.). Gamblers Anonymous (3rd ed.). Los Angeles, CA: G.A. Pub.

Goldstein, R. Z., \& Volkow, N. D. (2011). Dysfunction of the prefrontal cortex in addiction: Neuroimaging findings and clinical implications. Nature Reviews Neuroscience, 12, 652-669. https://doi.org/10.1038/nrn3119 
Gordon, E. (2016, June). Reframing the language of addiction: Researcher pushes to strike the term "abuse." Side Effects. Retrieved from http://www.sideeffectspublicmedia.org/post/reframing-languageaddiction-researcher-pushes-strike-term-abuse

Grant, J. E., Potenza, M. N., Weinstein, A., \& Gorelick, D. A. (2010). Introduction to behavioral addictions. The American Journal of Drug and Alcohol Abuse, 36, 233-241.

https://doi.org/10.3109/00952990.2010.491884

Greenfield, B. L., \& Tonigan, J. S. (2013). The general Alcoholics Anonymous tools of recovery: The adoption of 12 step practices and beliefs. Psychology of Addictive Behaviors, 27, 553-561. https://doi.org/10.1037/a0029268

Hallgren, K. A., \& McCrady, B. S. (2015). We-language and sustained reductions in drinking in couple-based treatment for alcohol use disorders. Family Process, 55, 62-78. https://doi.org/10.1111/famp.12150

Hill, A. B. (1965). The environment and disease: Association or causation? Journal of the Royal Society of Medicine, 58, 295-300. https://doi.org/10.1177/0141076814562718

Humphreys, K. (2003). Alcoholics Anonymous and 12-step alcoholism treatment programs. Recent Developments in Alcoholism, 16, 149164. https://doi.org/10.1007/0-306-47939-7_12

Humphreys, K., \& Moos, R. (2001). Can encouraging substance abuse patients to participate in self-help groups reduce demand for health care? A quasiexperimental study. Alcoholism: Clinical and Experimental Research, 25, 711-716.

https://doi.org/10.1097/00000374-200105000-00012

Humphreys, K., Wing, S., McCarty, D., Chappel, J., Gallant, L., Haberle, B., \& Weiss, R. (2004). Self-help organizations for alcohol and drug problems: Toward evidence-based practice and policy. Journal of Substance Abuse Treatment, 26, 151-158. https://doi.org/10.1016/s0740-5472(03)00212-5

Institute of Medicine. (1990). Broadening the base of treatment for alcohol problems. Washington DC: The National Academies Press.

Jin, S. R. (2005). The dialectical effect of psychological displacement: A narrative analysis. Taipei, China: National Science Council.

Jordan, K. N., \& Pennebaker, J. W. (2017). Trump's inaugural address. Retrieved from https://wordwatchers.wordpress.com/tag/authentic/ 
Kacewicz, E., Pennebaker, J. W., Davis, M., Jeon, M., \& Graesser, A. C. (2014). Pronoun use reflects standings in social hierarchies. Journal of Language and Social Psychology, 33, 125-143. https://doi.org/10.1177/0261927x13502654

Kalivas, P. W., \& Volkow, N. D. (2005). The neural basis of addiction: A pathology of motivation and choice. American Journal of Psychiatry, 162, 1403-13. https://doi.org/10.1176/appi.ajp.162.8.1403

Kaskutas, L. A. (1994). What do women get out of self-help? Their reasons for attending Women for Sobriety and Alcoholics Anonymous. Journal of Substance Abuse Treatment, 11, 185-195, https://doi.org/10.1016/0740-5472(94)90075-2

Kaskutas, L. A. (2009). Alcoholics Anonymous effectiveness: Faith meets science. Journal of Addictive Diseases, 28, 145-157. https://doi.org/10.1080/10550880902772464

Kelly, J. F. (2013). Does Alcoholics Anonymous work differently for men and women? A moderated multiple-mediation analysis in a large clinical sample. Drug and Alcohol Dependence., 130, 186-193. https://doi.org/10.1016/j.drugalcdep.2012.11.005

Kelly, J. F. (2017). Is Alcoholics Anonymous religious, spiritual, neither? Findings from 25 years of mechanisms of behavior change research. Addiction, 112, 929-936. https://doi.org/10.1111/add.13590

Kelly, J. F. (2018). Commentary on Tonigan et al. (2018): Clarifying the evidence for the clinical and public health utility of Alcoholics Anonymous for dual-diagnosis patients. Addiction., 113, 1982-1983. https://doi.org/10.1111/add.14390

Kelly, J. F., \& Beresin, G. (2014). In defense of 12 steps: What science really tells us about addiction. Common health: Reform and reality. Retrieved from https://www.wbur.org/commonhealth/2014/04/07/defense-12-stepaddiction

Koerner, B. (2018, October 23). It started as an online gaming prank, then it turned deadly. WIRED. Retrieved from https://www.wired.com/story/swatting-deadly-online-gaming $\operatorname{prank} /$ ?mbid=email_onsiteshare

Kornfield, R., Toma, C. L., Shah, D. V., Moon, T. J., \& Gustafson, D. H. (2018). What do you do before you relapse? How language use in a peer-to-peer online discussion forum predicts risky drinking among 
those in recovery. Health Communication, 33, 1184-1193.

https://doi.org/10.1080/10410236.2017.1350906

Krentzman, A. R., Brower, K. J., Cranford, J. A., Bradley, J. C., \&

Robinson, E. A. (2012). Gender and extroversion as moderators of

the association between Alcoholics Anonymous and sobriety. Journal of Studies on Alcohol and Drugs, 73, 44-52.

https://doi.org/10.15288/jsad.2012.73.44

Krentzman, A. R., Robinson, E. A., Moore, B. C., Kelly, J. F., Laudet, A. B., White, W. L., \& Strobbe, S. (2010). How Alcoholics Anonymous (AA) and Narcotics Anonymous (NA) work: Cross-disciplinary perspectives. Alcohol Treatment Quarterly, 29, 75-84. https://doi.org/10.1080/07347324.2011.538318

Kross, E., Ayduk, O., \& Mischel, W. (2005). When asking "why" does not hurt: Distinguishing rumination from reflective processing of negative emotions. Psychological Science, 16, 709-715.

https://doi.org/10.1111/j.1467-9280.2005.01600.x

Kurtz, L. F. (2017). The recovery community as a location for secular spirituality. Addiction, 112, 939-940. https://doi.org/10.1111/add.13716

Litt, M. D., Kadden, R. M., Kabela-Cormier, E., \& Petry, N. M. (2009). Changing network support for drinking: Network support project 2year follow-up. Journal of Consulting \& Clinical Psychology, 77, 229242. https://doi.org/10.1037/a0015252

Longabaugh, R., Wirtz, P. W., Zweben, A., \& Stout, R. L. (1998). Network support for drinking, Alcoholics Anonymous and long-term matching effects. Addiction, 93, 1313-1333. https://doi.org/10.1046/j.13600443.1998.93913133.x

Lubin, G. (2011, October 18). The 19 jobs where you're most likely to kill yourself. Business Insider. Retrieved from https://www.businessinsider.com/most-suicidal-occupations-2011-10

Maxwell, M. (1982). Alcoholics Anonymous. In E. Gomberg, H. White, \& J. Carpenter (Eds.), Alcohol, science and society revisited (pp. 295305). Ann Arbor, MI: The University of Michigan Press.

McCrady, B. S. (1994). Alcoholics Anonymous and behavior therapy: Can habits be treated as diseases? Can diseases be treated as habits? Journal of Consulting and Clinical Psychology, 62, 1159-66. https://doi.org/10.1037//0022-006x.62.6.1159 
McHugh, R. K., Kaufman, J. S., Frost, K. H., Fitzmaurice, G. M., \& Weiss, R. D. (2013). Positive affect and stress reactivity in alcoholdependent outpatients. Journal of Studies on Alcohol and Drugs, 74, 152-157. https://doi.org/10.15288/jsad.2013.74.152

Mendola, A., \& Gibson, R. (2016). Addiction, 12-step programs, and evidentiary standards for ethically and clinically sound treatment recommendations: What should clinicians do? AMA Journal of Ethics, 18, 646-655. https://doi.org/10.1001/journalofethics.2016.18.6.sect1-1606

Moos, R. H., \& Moos, B. S. (2006). Participation in treatment and Alcoholics Anonymous: A 16-year follow-up of initially untreated individuals. Journal of Clinical Psychology, 62, 735-750. https://doi.org/10.1002/jclp.20259

Narcotics Anonymous World Services. (1993). It works, how and why: The twelve steps and twelve traditions of Narcotics Anonymous. Van Nuys, CA: Author.

Newman, M. L., Pennebaker, J. W., Berry, D. S., \& Richards, J. M. (2003). Lying words: Predicting deception from linguistic styles. Personality and Social Psychology Bulletin, 29, 665-675. https://doi.org/10.1177/0146167203029005010

NIDA. (2013, June 1). Seeking drug abuse treatment: Know what to ask. Retrieved from https://www.drugabuse.gov/publications/seekingdrug-abuse-treatment-know-what-to-ask

Overeaters Anonymous. (2018). The twelve steps and twelve traditions of Overeaters Anonymous (2nd ed.). Rio Rancho, NM: Overeaters Anonymous.

Owen, P. L., Slaymaker, V., Tonigan, J. S., McCrady, B. S., Epstein, E. E., Kaskutas, L. A., Miller, W. R. (2003). Participation in Alcoholics Anonymous: Intended and unintended change mechanisms. Alcoholism: Clinical and Experimental Research, 27, 524-532. https://doi.org/10.1097/01.alc.0000057941.57330.39

Pennebaker Conglomerates. (n.d.) About us. Retrieved from http://www.pennebakerconglomerates.com/about-us.html

Pennebaker, J. W., Booth, R. J., Boyd, R. L., \& Francis, M. E. (2015). Linguistic inquiry and word count: LIWC2015. Austin, TX: Pennebaker Conglomerates.

Pennebaker, J. W., Boyd, R. L., Jordan, K., \& Blackburn, K. (2015). The development and psychometric properties of LIWC2015. Retrieved 
from

https://repositories.lib.utexas.edu/bitstream/handle/2152/31333/LI

WC2015_LanguageManual.pdf

Pennebaker, J. W., Chung, C. K., Frazee, J., Lavergne, G. M., \& Beaver,

D. I. (2014). When small words foretell academic success: The case of college admissions essays. PloS one, 9, e115844.

Project MATCH Research Group. (1998). Matching alcoholism treatment to client heterogeneity: Project MATCH three-year drinking outcomes. Alcoholism: Clinical and Experimental Research, 22, 1300-1311. https://doi.org/10.1111/j.1530-0277.1998.tb03912.x

Quinones, S. (2016). Dreamland: The true tale of America's opiate epidemic. New York, NY: Bloomsbury Press.

Raikhel, E. (2015). From the brain disease model to ecologies of addiction. In L. J. Kirmayer, R. Lemelson, \& C. A. Cummings, C. A. (Eds.), Re-visioning psychiatry: Cultural phenomenology, critical neuroscience, and global mental health. Retrieved from https://ebookcentral.proquest.com

Rentscher, K. E., Soriano, E. C., Rohrbaugh, M. J., Shoham, V., \& Mehl, M. R. (2017). Partner pronoun use, communal coping, and abstinence during couple focused intervention for problematic alcohol use. Family Process, 56, 348-363. https://doi.org/10.1111/famp.12202

Rude, S., Gortner, E. M., \& Pennebaker, J. (2004). Language use of depressed and depression-vulnerable college students. Cognition \& Emotion, 18, 1121-1133. https://doi.org/10.1080/02699930441000030

Serafini, K., Malin-Mayor, B., Nich, C., Hunkele, K., \& Carroll, K. M. (2016). Psychometric properties of the Positive and Negative Affect Schedule (PANAS) in a heterogeneous sample of substance users. The American Journal of Drug and Alcohol Abuse, 42, 203-212. https://doi.org/10.3109/00952990.2015.1133632

Slote Morris, Z., Wooding, S., \& Grant, J. (2011). The answer is 17 years, what is the question: Understanding time lags in translational research. Journal of the Royal Society of Medicine, 104, 510-520. https://doi.org/10.1258/jrsm.2011.110180

Stephenson, G. M., Laszlo, J., Ehmann, B., Lefever, R. M., \& Lefever, R. (1997). Diaries of significant events: Socio-linguistic correlates of therapeutic outcomes in patients with addiction problems. Journal of Community \& Applied Social Psychology, 7, 389-411. 
https://doi.org/10.1002/(sici)1099-1298(199712)7:5<389::aidcasp434>3.3.co;2-i

Tausczik, Y., \& Pennebaker, J. (2010). The psychological meaning of words: LIWC and computerized text analysis methods. Journal of Language and Social Psychology, 29, 24-54.

https://doi.org/10.1177/0261927x09351676

TED. (2015, July 9). Johann Hari: Everything you think you know about addiction is wrong [Video file]. Retrieved from https://youtu.be/PY9DcIMGxMs

Toft, D. (2000). Recent research offers compelling support for the effectiveness of twelve step-based treatment. The Voice. Retrieved from https://www.hazelden.org/web/public/vcsum0research.page

Vaillant, G. (2008). Spiritual evolution: A scientific defense of faith. New York, NY: Broadway Books.

Vederhus, J. K., Laudet, A., Kristensen, Ø., \& Clausen, T. (2010). Obstacles to 12-step group participation as seen by addiction professionals: Comparing Norway to the United States. Journal of Substance Abuse Treatment, 39, 210-217. https://doi.org/10.1016/j.jsat.2010.06.001

Walitzer, K. S., Dermen, K. H., \& Barrick, C. (2009). Facilitating involvement in Alcoholics Anonymous during out-patient treatment: A randomized clinical trial. Addiction, 104, 391-401. https://doi.org/10.1111/j.1360-0443.2008.02467.x

Weinberg, D. (2013). Post-humanism, addiction and the loss of self-control: Reflections on the missing core in addiction science. International Journal of Drug Policy, 24, 173-81.

https://doi.org/10.1016/j.drugpo.2013.01.009

Weisser, M. (2016). Practical corpus linguistics: An introduction to corpusbased language analysis. Chichester, England: Wiley Blackwell.

White, W. L. (1998). Slaying the dragon: The history of addiction treatment and recovery in America. Normal, IL: Chestnut Health Systems.

White, W. L. (2012). Are the AA and NA skies falling? Addiction Research \& Theory, 20, 105-106. https://doi.org/10.3109/16066359.2011.605969

Wilson, A. (2013). Embracing Bayes factors for key item analysis in corpus linguistics. In P. Lang (Ed.), New approaches to the study of linguistic variability (pp. 3-11). Frankfurt, Germany: Lancaster. 
Wilson, W. (1957). Alcoholics Anonymous comes of age. New York, NY: Alcoholics Anonymous World Services.

Wilson, W. (2001). Alcoholics Anonymous: The story of how many thousands of men and women have recovered from alcoholism. New York, NY: Alcoholics Anonymous World Services.

World Health Organization. (2018, June 18). WHO releases new International Classification of Diseases (ICD 11) [Press release]. Retrieved from http://www.who.int/news-room/detail/18-06-2018who-releases-new-international-classification-of-diseases-(icd-11)

Zemore, S. E. (2017). Implications for future research on drivers of change and alternatives to Alcoholics Anonymous. Addiction, 112, 940-942. https://doi.org/10.1111/add.13728

Zemore, S. E., \& Kaskutas, L. A. (2009). Development and validation of the Alcoholics Anonymous Intention Measure (AAIM). Drug \& Alcohol Dependence, 104, 204-211.

https://doi.org/10.1016/j.drugalcdep.2009.04.019 
Table 1

Results for Linguistic and Psychological Processes

\begin{tabular}{llllllllll}
\hline Category & Process & AA & DA & GA & NA & OA & SLAA & LL & BIC \\
\hline Analytic & Psycholing. & 597 & 1181 & 103 & 1763 & 726 & 1664 & $163.34^{* *}$ & Very Strong \\
Authentic & Psycholing. & 102 & 891 & 35 & 979 & 407 & 861 & $380.53^{* *}$ & Very Strong \\
Tone & Psycholing. & 190 & 442 & 14 & 725 & 327 & 768 & $181.45^{* *}$ & Very Strong \\
1st-p sg. & Linguistic & 0 & 18 & 0 & 6 & 0 & 0 & $45.09^{* *}$ & Weak \\
3rd-p sg. & Linguistic & 15 & 0 & 0 & 2 & 0 & 4 & $53.02^{* *}$ & Strong \\
1st-p pl. & Linguistic & 50 & 207 & 27 & 394 & 200 & 196 & $75.3^{* *}$ & Very Strong \\
3rd-p pl. & Linguistic & 14 & 7 & 1 & 10 & 3 & 10 & $16.93^{* *}$ & Very Strong \\
Male & Physical & 16 & 0 & 0 & 2 & 0 & 3 & $57.76^{* *}$ & Very Strong \\
Bio & Physical & 38 & 40 & 4 & 145 & 112 & 147 & $87.94^{* *}$ & Very Strong \\
\hline$*<.05, * *$ & $p<.01$ & & & & & & & &
\end{tabular}


Table 2

Post Hoc Results for Broad Psycholinguistic, Linguistic, Psychological, and Physical Processes

\begin{tabular}{|c|c|c|c|}
\hline Category & Corpus & $L L$ & $\mathrm{BIC}$ \\
\hline Analytic & GA & $37.23^{* *}$ & 28 \\
\hline Analytic & $\mathrm{OA}$ & $57.27 * *$ & 48.05 \\
\hline Analytic & SLAA & $99.04^{* *}$ & 89.81 \\
\hline Authentic & $\mathrm{AA}$ & $233.71^{* *}$ & 224.49 \\
\hline Authentic & $\mathrm{DA}$ & $86.17^{* *}$ & 76.95 \\
\hline Authentic & GA & $52.99^{* *}$ & 43.76 \\
\hline Authentic & $\mathrm{OA}$ & $23.98^{* *}$ & 14.75 \\
\hline Authentic & SLAA & $31.55^{* *}$ & 22.33 \\
\hline Tone & $\mathrm{AA}$ & $16.91^{* *}$ & 7.68 \\
\hline Tone & $\mathrm{DA}$ & $10^{* *}$ & 0.77 \\
\hline Tone & GA & $70.63^{* *}$ & 61.41 \\
\hline Tone & $\mathrm{OA}$ & $9.41^{* *}$ & 0.19 \\
\hline Tone & SLAA & $107.56^{* *}$ & 98.33 \\
\hline $1^{\text {st }}$-person sing. & $\mathrm{DA}$ & $33.23^{* *}$ & 24.01 \\
\hline $1^{\text {st }}$-person sing. & SLAA & $11.94^{* *}$ & 2.72 \\
\hline $3^{\text {rd }}$-person sing. & $\mathrm{AA}$ & $44.85^{* *}$ & 35.62 \\
\hline $3^{\text {rd }}$-person sing. & $\mathrm{DA}$ & $9.65^{* *}$ & 0.43 \\
\hline $1^{\text {st }}$ person pl. & AA & $11.94^{* *}$ & 2.72 \\
\hline $1^{\text {st }}$-person pl. & NA & $29.38 * *$ & 20.16 \\
\hline $1^{\text {st }}$-person pl. & SLAA & $9.75^{* *}$ & 0.53 \\
\hline $3^{\text {rd }}$-person pl. & $\mathrm{AA}$ & $14.98^{* *}$ & 5.75 \\
\hline Male & $\mathrm{AA}$ & $51.67^{* *}$ & 42.45 \\
\hline Male & $\mathrm{DA}$ & $9.61^{* *}$ & 0.38 \\
\hline Bio & $\mathrm{DA}$ & $54.69 * *$ & 45.47 \\
\hline Bio & GA & $10.5^{* *}$ & 1.28 \\
\hline Bio & $\mathrm{OA}$ & $19.31^{* *}$ & 10.09 \\
\hline Bio & SLAA & $17.23^{* *}$ & 8.01 \\
\hline
\end{tabular}

